\title{
Initial DAB Argon Storage Dewar Leakage
}

3740.512-EN-255

\author{
May, 3009 \\ K. Dixon
}

checked by:T180achecen 6/25/90 


\section{Introduction}

Any detectable leakage emanating from the argon storage dewar is undesirable; not only from a safety standpoint ( $\theta$, cryogenic burns, asphyxiation, etc.), but also small amounts of air back diffusing through leaks can render the argon unsuitable for the future physics experiments to take place within the cryostats. Whereas leakage through some of the control and manually operated valves on the dewar does not necessarily introduce any of the above hazards directly, it could be high enough to be an economical, and perhaps an operational nuisance. Contained in the following is a compilation of the final leakage rates associated with the dewar during the period of January through May of 1990 and the raw data from which they were derived from. Also contained is a calculation of the total maximum allowable leakage rate into/out of the dewar.

The general strategy employed while leak checking the dewar was to eliminate all leaks found which could be relatively easily stopped and to reduce the more difficult ones to an acceptable level. Leakage past the seats/plugs of control and main relief valves in addition to leakage past the ball seals in the diverter valve fell into the latter category. Helium mass spectrometer leak detector (HMSLD), rate of rise (ROR) method, and throughput calculations based on effective pumping speeds were the means used to determine leakage rates. Usually the HMSLD method was used to detect the numerous smaller leaks $(10 \mathrm{E}-5$ to $10 \mathrm{E}-10 \mathrm{std} \mathrm{cc} / \mathrm{s})$ which were eventually stopped by thread tightening, gasket replacement, redesign, etc. The ROR method helped measure the leakage past valve plugs and establish outgassing rates for volumes deemed as being tight; ie, no detectable leakage using the HMSLD. The throughput calculation was used only to determine the relatively large leak past the plug/seat of the vaporizer valve.

A sample calculation of each leakage rate determining method is attached to this note. All leakage rates are given for helium gas at one atm differential.

\section{Results}

\section{Plug/Seat Leakage}

Based on ROR

$$
\text { VALVE -FUNCTION }
$$

Control Valves:
PV611A-gAr to cryostats PV625A-IAr from trailer PV638A-IAr to cryostats

$\begin{array}{cc}\begin{array}{c}\text { ISOLATED } \\ \text { VOLUME }\end{array} & \text { ROR } \\ 330 \mathrm{cc} & 4 \mu / \mathrm{min} \\ 330 \mathrm{cc} & 1 \mu / \mathrm{min} \\ 330 \mathrm{cC} & 3 \mu / \mathrm{min}\end{array}$

LEAKAGE RATE

9.1E-6 std cc/s He

1.1E-6 std cc/s

$6.9 \mathrm{E}-6 \mathrm{std} \mathrm{cc} / \mathrm{s}$ 
3740.512-EN-254 Initial DAB Argon Storage Dewar Leakage 5/29/90

$\begin{array}{rrrr}\text { Manual Valves: MV617A-diverter, low } & 1440 \mathrm{cc} & <0.15 \mathrm{psi} / \mathrm{day} & <8 \mathrm{E}-3 \mathrm{std} \mathrm{cc} / \mathrm{s} \\ \text { MV617A-diverter, high } & 1080 \mathrm{cc} & 1 \mathrm{psi} / \mathrm{day} & 5 \mathrm{E}-2 \mathrm{std} \mathrm{cc} / \mathrm{s}\end{array}$

Based on HMSLD

VALVE-FUNCTION SENSITIVITY READING LEAKAGE

RATE

Main Relief Valves: PSV620A-16 psig set

$1.8 \mathrm{E}-10 \mathrm{std} \mathrm{cc} / \mathrm{s} \quad 20 \times 500 \quad 1.8 \mathrm{E}-6 \mathrm{std} \mathrm{cc} / \mathrm{s}$

PSV619A-65 psig set $1.5 \mathrm{E}-10 \mathrm{std} \mathrm{cc} / \mathrm{s} \quad 68 \times 500 \quad 5.1 \mathrm{E}-6 \mathrm{std} \mathrm{cc} / \mathrm{s}$

Based on Piping/Pump Throughput

VALVE-FUNCTION

Control Valves: PV601A-vaporizer control

$\begin{array}{ccc}\text { PUMPING } & \text { PRESSURE } & \text { LEAKAGE } \\ \text { SPEED } & \text { RATE } \\ 2600 \mathrm{cc} / \mathrm{s} & 8 \mu & 8.5 \mathrm{E}-2 \mathrm{std} \mathrm{cc} / \mathrm{s}\end{array}$

\section{Other}

Based on ROR

ISOLATED VOLUME

ROR

LEAKAGE

RATE

Dewar:

7.6E7 cc

$0.4 \mu / d a y$

$6.2 \mathrm{E}-5 \mathrm{std} \mathrm{cc} / \mathrm{s}$

Based on HMSLD

Miscellaneous items to include: all piping and tubing, flanges, valve packings, gages transmitters, thermal relief valves, rupture disks, shut off valve plug/seats, internal condenser and bayonet caps. All gave no indication on the detector which yields a maximum leakage of $1.8 \mathrm{E}-10 \mathrm{std} \mathrm{cc} / \mathrm{s}$ He per item.

\section{Discussion}

The maximum allowable total leakage into/from the dewar has been found to be 3.1E-4 std cc/s He by calculation. This assumes that a $0.1 \mathrm{ppm}$ oxygen impurity level is not to be exceeded for a 5 year period. The only leakage found that exceeds this requirement is past the ball seals of the diverter valve and through the plug/seat of the the control valve for the vaporizer. The only other leakage rate that comes close to this upper level is the final ROR of the dewar volume itself. This, however is due to outgassing of the walls and piping and is thought of primarily as a base number for future reference.

Leakage past the ball seals has been found to be much greater than the calculated maximum. This has been determined not to be a problem for the following : 
the maximum pressure to the uploading or high relief side can be no greater than 16 psig and any leakage through the diverter is stopped at the rupture disk or relief valve, both of which leak less than the maximum allowed; since the leakage through to the leak "tight" low pressure reliefs is far less than that to the higher side and given the fact that the diverter will only leak to the low pressure side during very infrequent trailer fill operations, leakage past the diverter valve is acceptable in both directions.

A calculation attached to this note assumes that all argon gas leakage past the seat/plug of the vaporizer control valve is equivalent to a liquid flow which is vaporized. The vaporization per day due to this leakage adds only $1 \%$ to the total amount expected as listed in the vendor dewar specifications. Although this calculation appears to use conservative assumptions, it does not take into account any reduction of seating force due to the differential contraction between the plastic plug material and its metal seat. This effect should be insignificant but the heat leak will be closely monitored during the initial fill of the dewar.

\section{Conclusions}

The 20,000 gallon argon storage dewar inside of DØ Assembly Building has been thoroughly leak checked and has been determined to be "tight" or leaks far less than maximum levels established by calorimeter physics, operational or economic concerns. 


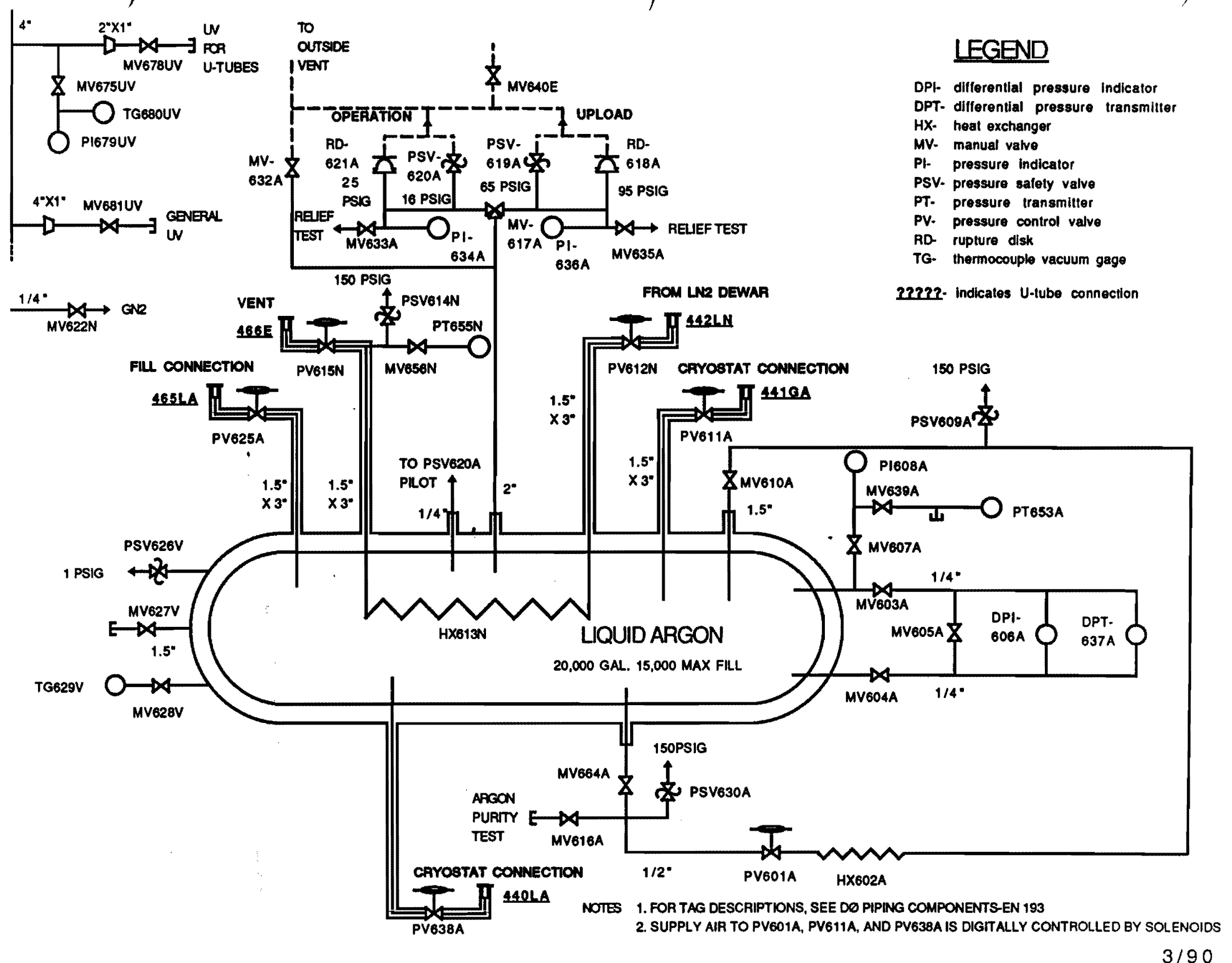




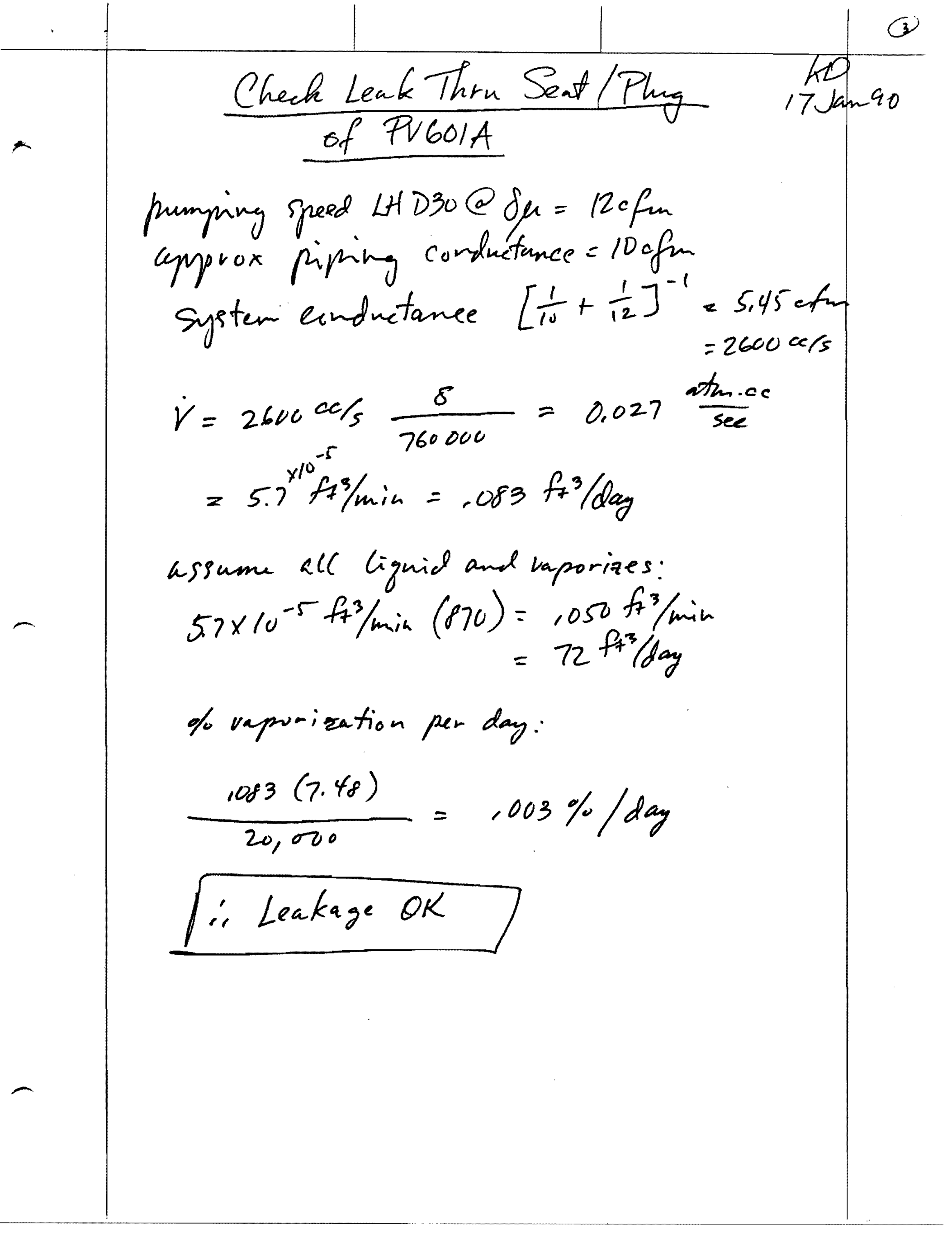




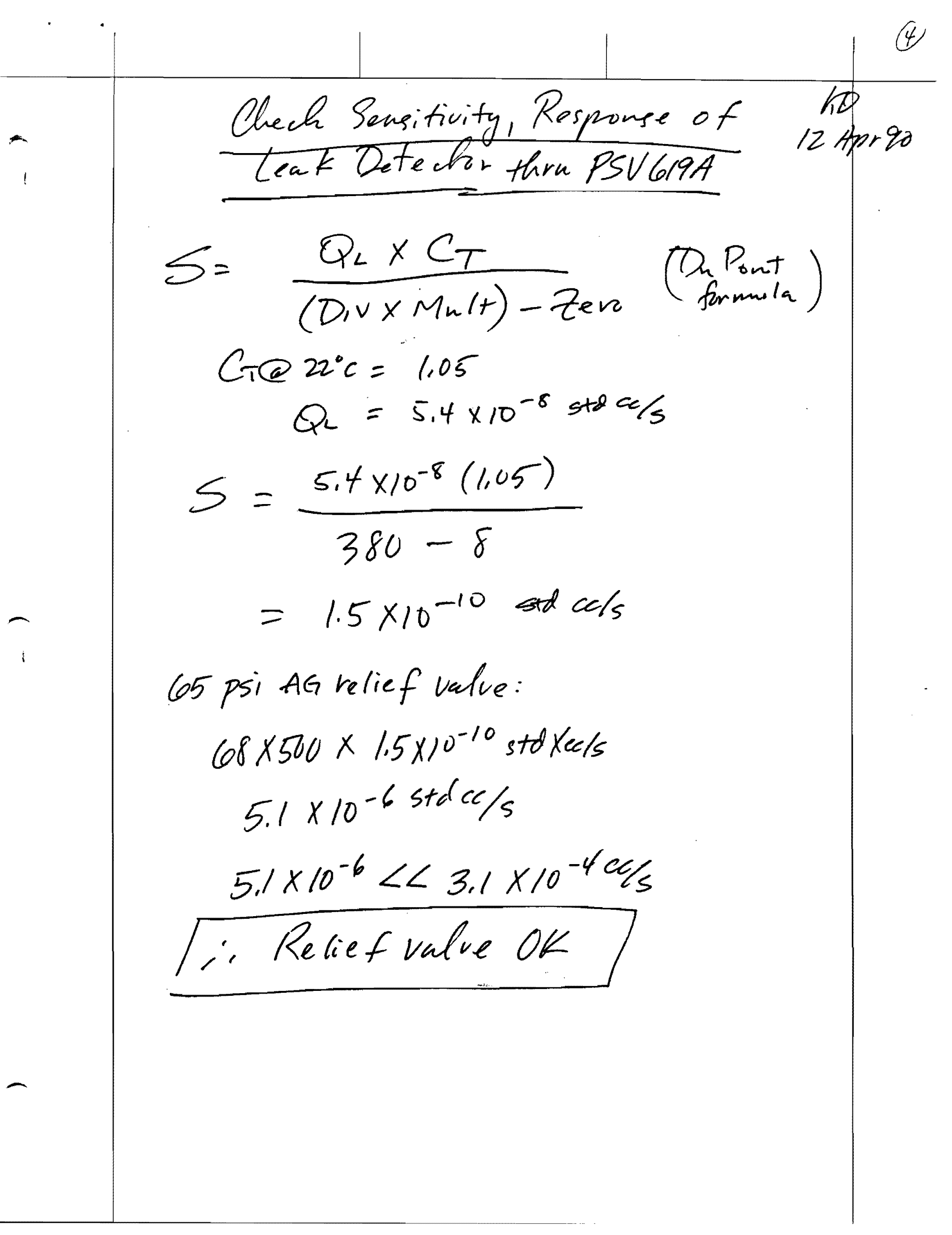


Determine the Maximum Leakage Rate 25 Apr 80 into liquid Argon Volumes

$$
\frac{V_{O_{2}}}{V_{A_{2}}}=10^{-7} \quad(0.1 \mathrm{ppm})
$$

if we want this purity for 5 years, then

$$
\begin{aligned}
& \dot{V}_{O_{2}}=\frac{10^{-7}}{5 y \text { rs }} V_{\text {Ar }} \\
& \text { let } V_{A r}=870 \mathrm{VeAr} \\
& \dot{V}_{O_{2}}=\frac{10^{-7}(870)}{\left(\pi \times 10^{7} \mathrm{~s}\right)(5)} V_{\text {eAr }} \\
& \dot{V}_{O_{2}}=5.5 \times 10^{-13} V_{\text {lAr }}(1 / \mathrm{s}) \Rightarrow \max _{\text {for }} 5 \text { year wear }
\end{aligned}
$$

for diffusional flow molecular regimes.

$\dot{v}_{\text {in }} \cong \dot{V}_{\text {out }}$ at low pressures $(\lambda \leq d)$ $\dot{V} \propto \frac{1}{\sqrt{m}}$

mean free Mire

$$
\begin{aligned}
& \dot{V}_{\text {He }}=\dot{V}_{\text {ain }} \sqrt{\frac{29}{4}} \\
& \dot{V}_{\mathrm{O}_{2}} \cong 0.2 \dot{V}_{\text {ain }} \quad \dot{V}_{\text {ain }} \simeq 5 \dot{V}_{\mathrm{O}_{2}} \\
& \dot{V}_{\mathrm{He}}=5 \dot{V}_{\mathrm{O}_{2}} \sqrt{\frac{29}{4}} \\
& \dot{V}_{\mathrm{He}}=13.5 \dot{V}_{\mathrm{O}_{2}}
\end{aligned}
$$




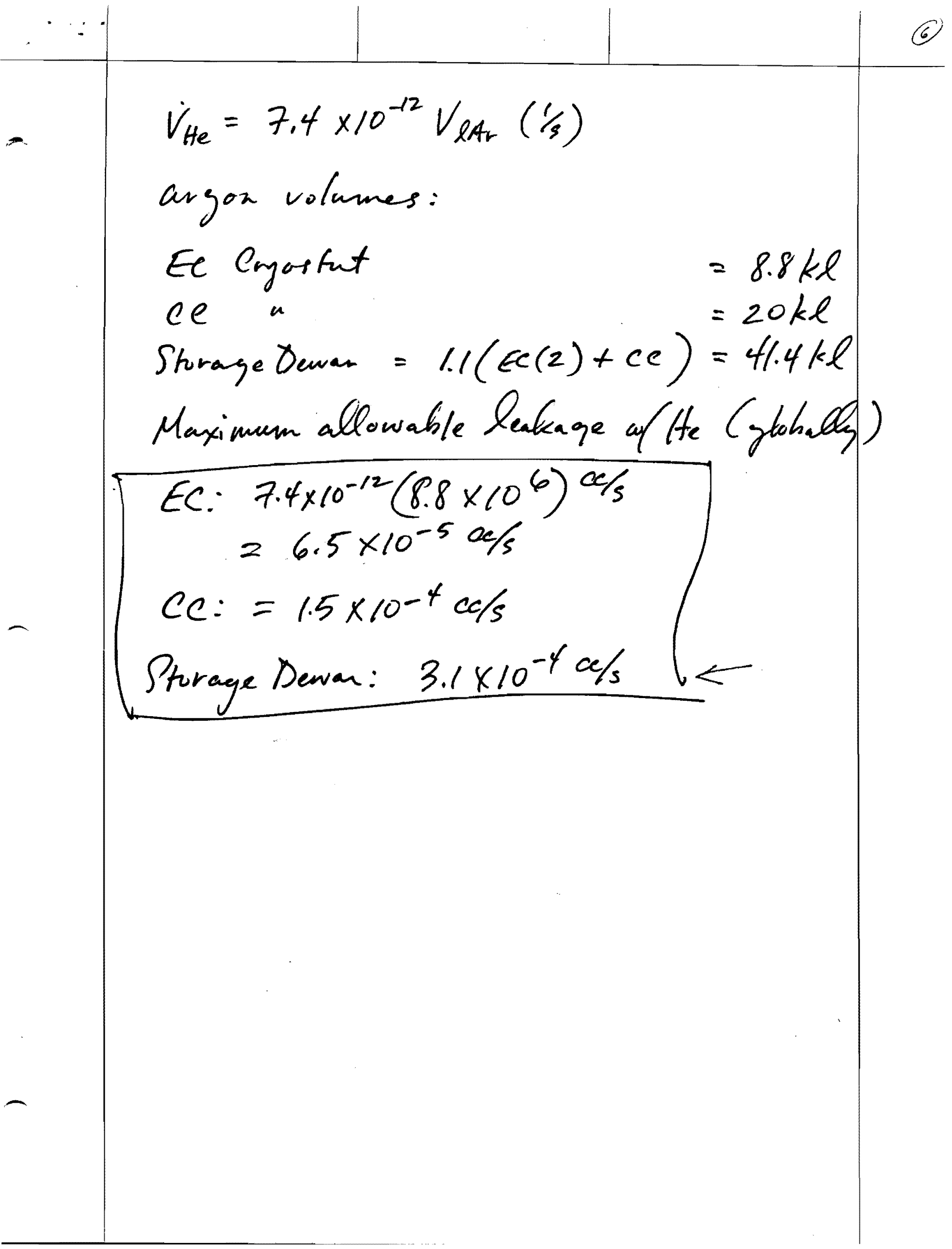

